\title{
On Enhancing Students' Discourse Competence in Reading
}

\author{
Hui Pan \\ Wenzhou Medical University, Wenzhou 325035, Zhejiang, China \\ Email: emikoph@163.com
}

\begin{abstract}
Discourse competence, as important index in discourse analysis, plays an important role in developing learners' receptive and productive skills in English. With good discourse competence, learners can understand spoken or written texts better, both at the local and global levels. Besides, they can produce more cohesive discourse to promote their speaking and writing abilities. However, English teaching classroom often focuses heavily on linguistic competence, weighing too much on vocabulary, and grammar. This paper aims to explore the relationship between cohesion and coherence and how to develop students' discourse competence in reading.
\end{abstract}

Keywords: discourse competence, cohesion and coherence, reading

\section{Introduction}

With the popularity of communicative language teaching (CLT), more and more teachers realize that apart from linguistic competence, they should also try to cultivate students' grammatical competence and discourse competence. Canale and Swain (1980: 47) propose the notion of communicative competence and emphasize language learning and language use in social context. This is different from Chomsky's language acquisition device, which regards language learning as a cognitive behavior, independent of context and occurring in learner's brain. Canale and Swain (1980: 45) include linguistic competence, sociolinguistic competence, discourse competence, and strategic competence as the four components of communicative competence. Among them, discourse competence is related to the learners' mastery of understanding and producing texts in the modes of listening, speaking, reading and writing. It deals with cohesion and coherence in different types of texts.

Cohesion and coherence, as index in discourse analysis, are important for both receptive skills and productive skills. It is stated in many official documents, as important weight to mark writing and speaking. American Common Core State Standard (CCSS) articulates the emphasis on coherence even at the kindergarten stage, requiring that kindergartners should "tell about the events in order in which they occurred" (p.19). UK national curriculum also states that "effective composition involves forming, articulating and communicating ideas, and then organizing them coherently for a reader" (p.16). In many international tests such as IELTS and TOEFL, coherence is an important marking criterion for writing. In China, students are also required to write English compositions coherently. Chinese national curriculum for English has clearly stated it at every stage, from primary school to university level. Such focus on coherent writing has been validated by research. Lee's case study, conducted at the Hongkong Polytechnic University, has indicated that explicit teaching has "increased students' awareness of a particular facet of coherence" and help students to write better (2002). The study further indicates that a weak demand of grammar and vocabulary hinders coherence in writing.

However, teaching cohesion and coherence is neglected in English language teaching. Guy Cook (1989) points out that cohesion has been neglected in language teaching, where sentences are formulated, used, and assessed in isolation. The reason is that current language teaching assumes that lack of vocabulary and sentence-level grammatical structure is the major hinderance to language learning. Nevertheless, problems with cohesion can also easily cause difficulties in reading and writing. When reading, it is quite common that learners can understand every word in every sentence, but still not understanding the whole meaning. When writing, students can create grammatically correct sentences, but incoherent or inappropriate. Besides, the English language's different features require that teachers should pay more attention to cohesion, because cohesion is realized by lexical cohesive devices. In other words, vocabulary plays a critical role to establish cohesion and coherence in English. However, it is common that in cohesion teaching, more attention is paid to grammatical cohesive devices, such as substitution, and conjunctions, which leads to the overuse of connectors among students, such as furthermore, next, and besides. In fact, native speakers use more lexical cohesive devices than grammatical ones to create coherence. Therefore, as language teachers, we should address the issue in a comprehensive way and teach cohesion and coherence explicitly to students. 


\section{A brief introduction of cohesion and coherence}

\subsection{Understanding cohesion}

Cohesion is a semantic concept and refers to the relations of meaning existing within the text (Halliday \& Hasan, 1976: 4). Cohesion occurs when the meaning of some element in the discourse depends on that of another, that is, it can only be decoded by reference (ibid.). Similar statements are made by Bublitz (2011: 37) saying that cohesion, as a kind of textual prosody, refers to inter-sentential semantic relations that links current items with preceding or following ones by lexical and structural means. He further claims that cohesion is invariant property of a piece of discourse or text which is independent of user and context. Cohesion is the grammatical and lexical relationships which tie a text together, which falls into the lowest level of discourse domain (Cook, 1989).

There are many ways to make texts cohesive. These cohesive devices or linking devices, which are also called "formal links" by Guy Cook (1989), are put into different categories. The most traditional category is Halliday and Hasan's five types of cohesion, which are reference, substitution, ellipsis, conjunction, and lexical cohesion (1976). Among those, reference, substitution, and ellipsis are grammatical cohesive devices, and conjunctions are logical cohesive devices. Following Halliday and Hasan's proposal, much effort has been put into re-classifying and extending their itemization of cohesive means (Cook, 1989; Bublitz, 2011). Guy Cook (1989) adds "parallelism" to the cohesion family, and Thornbury (2005) puts rhetorical cohesion into his three categories (the other two are lexical and grammatical cohesion).

\subsection{Understanding coherence}

Coherence is "the quality of being meaningful and unified" (Cook, 1989: 4). From this definition, we can see that there are two requisites for the text to be coherent. On the one hand, it should be unified, which means that a text is connected by all kinds of devices and its content is coherent and relevant. On the other hand, the text should be meaningful in the eyes of the reader. Like what Thornbury (2005: 36)says, coherence is the capacity of a text to "make sense" or meaningful and the quality that the reader derives from the text, not simply a function of cohesion. In fact, the above definition of coherence involves linguistic and non-linguistic aspects: coherence as internal to the text (linguistic) and coherence as internal to the reader (non-linguistic). The two aspects of coherence also reflect the different approaches to coherence: coherence as product and coherence as processing. In "coherence as product", the reader sticks to the text and tries to interpret it coherently with all kinds of cohesive devices, while in "coherence as processing", the reader brings his own prior knowledge to achieve coherent interpretation. The difference in the two perspectives can be summarized with the statement that discourse has coherence while the text has cohesion (Widdowson, 1978; Seidlhofe \& Widdowson, 1999). The explanation reflects the importance of the interpreter in realizing coherence.

\subsubsection{Linguistic view of coherence}

In linguistics, coherence can be defined as the property of the text. Halliday and Hasan (1976) look to the formal properties of language when attempting to elaborate "texture", whose notion is the same as coherence. In Halliday and Hasan's opinion, cohesive devices can help writers tie the text together and guide the reader to build the coherent interpretation proposed by the writer (1976). Functional sentence perspective introduces the notion of "given and new" (Kopple 1983), "theme and rheme" (Halliday, 1985; Halliday \& Matthiessen, 2014) and "topic and comment" (Gundel, 1975). Those terms and patterns devote themselves to micro-level coherence. On the other hand, Kintsch and Van Dijk (1983) depict coherence at the local (micro) and global (macro) level. Local coherence is the cohesion relation between nearby clauses in the text while global coherence is the links between groups of clauses and groups of paragraphs. Some linguistics looks at both the lexical patterns and macrostructure of the text (Hoey, 1991), or metadiscoursal features (Cheng $\&$ Steffensen, 1996) to explain coherence.

\subsubsection{Non-linguistic view of coherence}

From non-linguistic perspective, readers play important roles in constructing the coherence of texts. The reader's prior knowledge and experience contribute to the construction of coherence. According to Bamberg (1983), prior knowledge and experience "help readers anticipate upcoming textual information, thereby enabling them to reduce and organize the text into an understandable and coherent whole" (P.419). Similar claims are made by Brown and Yule (1983: 25), saying that "... what the textual record means is determined by our interpretation of what the producer intended it to mean". In other words, whether a text is coherent or not is determined by the reader's interpretation. Unlike cohesion, which is invariant of reader and context, coherence of a text is dependent on its interpreter, based on the interaction between the reader and the text (Thornbury, 2005), is created while the reader is reading the text (McCathy, 1991). If a reader feels that a text hangs together and is united, or make sense, he would think that the text is coherent. On the contrary, if a reader feels that a text does not make sense, he would think that the text is not coherent, even though a lot of cohesive devices can be found in the 
text. Therefore, coherence is a cognitive category and a variant vector of discourse or text (Bublitz , 2011).

\section{Relationship between cohesion and coherence}

\subsection{Cohesion as the conditions of coherence}

From the above explanation, we know that the realization of coherence is determined by the text and the reader. As semantic connectivity as a condition for coherence (Bublitz, 2011), although it is a surface feature of texts and independent of the reader (Thornbury, 2005), cohesion can be a guide to coherence. The cohesive devices in spoken and written utterance may make the listener and the reader follow it easily, because they help the interpreter find the innate relationship by giving obvious signposts. Meanwhile, it is also true that a text is not coherent although it has sorts of cohesive devices, because the topic is not unified. Carrell makes the similar statement that "cohesion is not the cause of coherence; if anything, it's the effect of coherence" (1982: 486). The comments suggest that being cohesive is not the necessary condition of being coherent. A coherent text would be cohesive, but not necessary (ibid.). The interpreter would say that the text is cohesive only when he thinks that it is coherent.

\subsection{Coherence and the reader}

However, coherence is not realized only by cohesion. The reader is also crucial to coherence, whose world knowledge can help interpret a text coherently, even though it may have no cohesive devices. Examples of coherence without cohesion are quite common in both spoken and written discourse, such as the following one. "I'd love a cup of tea." "It's half past two already." Literally, the two sentences seem totally disconnected, but our interpretation is not hindered by this seemingly disconnection. With the context and our experience, it is not difficult for us to decipher them as this: one speaker wants to have a cup of tea, and the other speaker is discouraging him to do so, because it is too late. Therefore, it is possible to have a coherent discourse which is expressed by a text without any cohesive devices (Nuttall, 2005).

The next example indicates a different scenario, though. "Suddenly from the dark road ahead came a terrible screaming. Alice hid herself behind the tree." If we don't have the writer's assumption that screams are correlated with danger, horror or fear, we may have difficulty in understanding that the reason why "Alice hid herself behind the tree" is to protect himself from danger. It is the normal behavior when people are confronted with horror, fear, and danger. In other words, if we don't have the knowledge that "scream" often indicates "danger, horror, or fear", we could not interpret the texts coherently. To explain the issue, we need to discuss schema, an important factor to affect an interpreter's judgement of whether the text is coherent or not.

\subsection{Schema theory VS cohesion and coherence}

The background knowledge stored in our memory is called schema, which is proposed by Bartlett (1932: 197). Minsky develops an analogical term "frame" (1974: 1). It is the mental representation of typical scenarios. When activated, schema can serve to predict the content of the text and make sense of the discourse (Cook 1989), because we tend to interpret the text ("words-on-the-page") via the use of schema ("world-knowledge") based on how we have experienced in the past (Brown \& Yule, 1983: 233). Furthermore, schema/frame is a "remembered framework to be adapted to fit reality by changing details as necessary" (Minsky, 1974: 1). We have many schemata remembered in our memory and select appropriate one to fit in the utterance we have encountered. For example, in a "furniture" schema/frame, there are sofa, table, chair, wardrobe, bed, etc. When one encounters a new situation, he or she chooses an appropriate schema/ frame from his or her memory (Minsky, 1974). The selected schema also brings us some expectations to the utterance and guides us to make predictions, which makes the reader/listener flow the written/spoke discourse easily to facilitate coherent interpretation. Schema includes the language knowledge, the background information about the topic, previous experience, cultural background, and knowledge about text structure.

\subsection{Cohesion and coherence, to teach or not to teach?}

From above paragraphs, we can clear see that both cohesive devices and schema are important for us to create coherence. Therefore, I hold the stance that cohesion and coherence should be taught to English learners. As I have stated before, the importance can be seen in the two influential international language tests: IELTS and TOEFL, both of which put cohesion and coherence into their speaking and writing rubrics. Lee's case study, conducted at the Hongkong Polytechnic University, has indicated that explicit teaching has increased students' awareness to some extent and help them to write better (2002).

Cohesion and coherence are also essential for readers to interpret the text well. Studies have shown that readers have better comprehension of texts with more cohesion (Beck et al., 1984). Bamberg (1984) regards coherence as an important 
quality of effective reading. However, achieving cohesion and coherence in reading is not easy. On the one hand, as we have discussed in the previous sections, cohesion occurs when the meaning of some element in the discourse depends on that of another, that is, it can only be decoded by reference (Halliday \& Hasan, 1976: 4). Working out the reference of cohesive devices can help students identify the logical relation that exists in the text so that they can interpret it coherently. However, many English learners fail to do so because they lack required vocabulary or grammatic and syntactic knowledge. Lee's study supports the claim, finding that language proficiency affects learners' realization of coherence (2002). On the other hand, to achieve coherence, readers should have relevant schema, such as organization of sentences and paragraphs, rhetorical structures, and the shared knowledge between the reader and the writer, that is, the knowledge the writer assumes that readers should have to interpret the text (Nuttall, 1982, 2005). Therefore, learners' familiarity with the content topic and rhetorical structure can facilitate their coherent interpretation.

Thus, cohesion and coherence are important for students to improve their English level, which should be taught at all skill development stages. Awareness should be raised in every skill training and deserves great attention and exploration. During teaching, we should cultivate learners' coherence awareness at both micro and macro level. The cohesion analysis, building a structure by working "up" from a particular text and the schema theory, predicting structure from the schema "down" to the text are both central to coherence (Hatch, 1992). In this article, I am going to focus cohesion and coherence on English language reading in the next sections.

\section{Teach cohesion and coherence in reading}

\subsection{Variables affecting reading}

Current reading pedagogy regards reading as the interaction between the reader and the text. The reader brings his own background knowledge and previous experience when processing the text. In this sense, both the text and the reader influence the quality of reading. If the reader has relative schemata about the topic and text organization, he is more likely to interpret the text easily. Moreover, his master of grammatical and syntactical structure as well as vocabulary also plays an important role in reading. This view matches the above perspective of coherence: the reader is a great contributor to coherence achievement. If he thinks the text is united or makes sense, the text is coherent.

According to Alderson (2005), reader variables and text variables affect the nature of reading. Reader variables include background knowledge, language knowledge, knowledge of genre/text type, knowledge of the topic, knowledge of the world and culture, while text variables involve text topic and content, text type and genre, text organization, and text readability. If readers lack relevant knowledge featured in the text, they may have difficulty in interpreting it coherently. As Nuttall $(1982,2005)$ claims, problems in understanding texts lie in the issues of vocabulary and sentence structure, cohesive devices, discourse markers, and the relationships between the utterances in a text. Failure to identify the relationships between the utterances can explain the reason why a reader has understood every sentence but still is unable to "make sense of the text as a whole" (Nuttall, 1982: 83).

Carrell's (1984) shows the relationship between rhetorical structure and learners' recall outcomes and further claims the need of facilitating ESL reading by teaching text structure (1985). Studies have shown that the readers have better comprehension of texts if it has more cohesion (Beck et al., 1984). Many ESL writing textbooks teach sentencelevel grammar rather than coherence in a broader sense. (Oshima \& Hogue, 1991) It is quite common that students can understand every sentence but do not get the whole meaning of the text. The reason might be that they fail to find the correlation among paragraphs or sentences.

\subsection{The importance of teaching cohesion and coherence in reading}

It's important for language teachers to teach learners cohesion and coherence. Scholars suggest different methods to do so. Grabe and Kaplan (1996:76) have argued the significance of defining the concept of coherence in understanding how texts are constructed and further state that "defining the concept of coherence in some manageable way seems to be crucial to any understanding of hoe texts are constructed". Lee (2002) makes similar arguments, suggesting that language teachers should define coherence in more concrete terms. Nuttall (1982) suggests that cohesion may be tackled by identifying problems and then asking questions in which the meaning of the cohesive item is made explicit. The best way is to make use of every opportunity to draw attention to these features in the texts for other purposes.

The coherence of a text involves two levels: the global coherence and local coherence (Dijk \& Kintsch, 1983). Local coherence refers to the connection between adjacent sentences while global coherence refers to the semantic unity of the topic and the corresponding text structure (McCutchen \& Perfetti, 1982), which characterizes a discourse as a whole (Dijk et al.). Therefore, reading teaching should address topic coherence, local coherence, and cohesion. 
From the explanation of cohesion and coherence, we know that cohesion and the reader are essential to coherence. Cohesive devices are guide the reader or writer to obtain coherence. Besides, the reader or writer's schema is important for coherence. Local coherence involves connecting the currently processed information with the immediately preceding context (generally the previous one to three sentences), whereas global coherence involves establishing connections between currently processed information and information occurring much earlier in the text. Accordingly, I would address "how to teach cohesion and coherence" at three segments: teaching coherence at discourse topic level (global coherence), teaching coherence at sentence level (local coherence), and teaching cohesion.

\subsection{Teaching coherence}

\subsubsection{Teaching global coherence (teaching coherence at discourse topic level)}

A coherent written discourse is semantically integral, in which sentences are not only relevant to the topic, but also function to underline the structure of the discourse (McCutchen \& Perfetti, 1982). As Thornbury (2005) presents in his book Beyond the Sentence, headings and titles, key words, lexical chains and lexical patterns across long texts can all contribute to the realization of topic coherence. As we discussed above, readers' knowledge, schema, is also important. Therefore, the teacher should help students to activate the relevant schemata the text requires before reading.

(1) Brainstorming

Brainstorming is a good way to activate students' topic-related schema to facilitate coherent interpretation of the text. It also helps students evoke important content words in the text. To do this activity successfully, the teacher should provide topic-related questions. For example, if students are going to read an article about "stress", the teacher would ask them to discuss the following questions: Have you suffered from stress? In which circumstances do you feel stressful? How do you often do to get rid of it? Do you think stress is good or bad for you? Through discussion, students can activate their "stress" schema and elicit relevant words. If the teacher can draw an idea web on the blackboard after brainstorming. It can help students see interrelated relationship among different aspects of "stress", which also helps them know in what ways stress could be discussed

(2) Key words and lexical chains

Key words are those words that occur frequently in texts. To train students to identify key words, the teacher can divide a passage into several sections and give each of them to different groups. Students can work together to find the key words of each section. Or the teacher may himself take out the key words of each section and ask students to work out what the text is about. When discussing an article about stress, the teacher would give students the key words concerning "symptoms for stress", "causes for stress", "effects of stress", and "solutions to stress". Through class cooperation, they can work out the main idea about the text.

(3) Text Structure analysis and identifying the relationship among paragraphs

Analyzing text structure can help students understand the overall organization of the text and help them achieve global coherence. In this activity, students can be provided a relationship chart which shows how every paragraph is connected. Through analyzing the relationship among paragraphs, students can clearly understand how the text is structured and how the author supports his topic with details and examples. Afterwards, the teacher would ask students to go back to the article again to find all the discourse markers to show the relationship among paragraphs. Then students can get these lexically cohesive words. At the stage, the teacher should guide students to pay attention to where the cohesive devices are. Generally, they will find that these cohesive words are in the different parts of the article: at the beginning, in the middle, and at the end. If the teacher can tell students that the cohesive devices from different parts of the text function to tie the text together, students can have a good understanding of the text and also know how to create cohesion in their own writing.

After all the above tasks, students would know the structure of the article, aspects about the topic stress, as well underpinned relationship between paragraphs. In other words, they can interpret the topic coherently.

In addition, graphic organizers are good tools to help students to understand how the text is organized. The use of graphic organizers, altogether with students' knowledge of a certain genre, would help student interpret the text coherently in an easy way. Language teachers should help learners know the features of different genres so that they can choose appropriate organizers to show the development of the text. For example, if they know that biography is often organized in the chronological order, learners may probably use a timeline to help them understand when important events happened and find the logical relationship among all the happenings. An alternative for a timeline is ordering, sequencing sentences in the correct order based on the text.

(4) Identify the logical relationship by lexical cohesive devices

In English, most connectives are lexical cohesive devices. They are important tools for English writers to use to create 
cohesion, which sets higher vocabulary requirements for English learners. Poor vocabulary often prevents them from identifying the connection that is created by lexical cohesion. To raise learners' awareness of lexical cohesion through reading, a good practice is to guide them find all the connected devices. A table would help learners do so. For an article about "stress", the teacher would provide students with a table of four columns, in which the main sections "symptoms of stress", "cause for stress", "effect of stress", and "solutions" are the title of each column respectively. Students would be asked to find all the key words that describes each section in the text and use them to fill in the table. They are also asked to write down the paragraph number for each word. The table can show how everything concerning stress is connected between adjacent sentences and distant sentences. Besides, the teacher would ask students to mark the phrases in the same lexical chains with different colors. With this step, learners can see how the author uses lexical devices, such as original word repetition, synonyms, hypernyms/hyponyms, and antonyms, to create cohesion at both sentence (local) and paragraph (global) levels.

\subsubsection{Teaching local coherence (teaching coherence at sentence level)}

(1) Identify logical relationships

In reading texts, sentences are connected logically either explicitly or implicitly. Explicit connection is expressed with conjunctions like and, but, so, because, however. Implicit connection is often created with lexical cohesion, using the same words repeatedly, or using words to refer to one another in various way, such as using synonyms to express similar meaning and antonyms the opposite. Or using meronyms to referring to a whole, or hyponyms to refer to a class. Language teachers should highlight those words and help learners raise awareness of implicit logical connections.

(2) Topic-comment patterns in discourse

The tendency to place the new information in the latter part of a clause or sentence is called end-weight. The new information in the previous sentence often becomes the given information of the next sentence (Thornbury, 2005). The syntactic patterns connect the text together. Based on McCathy (1991), Thornbury (2005) develops the topic-comment patterns, which show how a paragraph or a text with several paragraphs can be organized. The patterns indicate a text may be tied together with end-weight, parallelism, or more complex structure. Teaching learners the principles helps them interpret the text in a coherent way. Such activities as identifying logical relations of sentences in the text, rogue sentences, and sentence insertion can help raise learners' logical relationships in the text.

\subsection{Teaching cohesion}

\subsubsection{Identify the meanings of references, substitutions, and ellipsis}

According to Thornbury (2005), identifying the meaning of reference, substitution, and ellipsis can raise learners' awareness of how they can be used to achieve cohesion. Therefore, language teachers should design activities to train learners' such ability.

\subsubsection{Find the words which are the synonym/antonym of the underlined word in the given sentence}

When students read outside the classroom, the teacher can design some activities aiming to cultivate students' awareness of cohesion and coherence. The exercises intend to help students understanding the meanings of the key words in the article and enlarge their vocabulary. In addition, other exercises can also be used, such as identifying the word which is different from others in the group, or categorizing the given words and naming the group. These exercises can not only enlarge students' vocabulary but also train them identify the relationship among words. They are good means for superordinate, synonym, and antonym awareness.

\section{Conclusion}

Coherence is an important index for good interpretation. Approaching coherence is a complicated process because it is affected by many factors. The text and the reader are both crucial elements for coherent interpretation. To help learners achieve coherent interpretation of texts, the teacher needs to focus on all types of cohesive devices, like grammatical cohesion, logical cohesion and lexical cohesion. In addition, the teacher needs to make the best use of the reader's role in reading, by activating and selecting appropriate schema to make coherence possible. Cohesion and coherence teaching are difficult, but every effort is worthwhile.

\section{References}

[1] Albrecht J.E., O'brien E.J. Updating a mental model: Maintaining both local and global coherence. Journal of Experimental Psychology: Learning, Memory, and Cognition. 1993; 19(5): 1061-1070. 
[2] Alderson J.C. Assessing Reading. Stuttgart: Ernst Klett Sprachen; 2005.

[3] Bamberg B. What makes a text coherent? College Composition and Communication. 1983; 34 (4): $417-429$.

[4] Bartlett F.C. Remembering: A Study in Experimental and Social Psychology. Cambridge: Cambridge University Press; 1932.

[5] Beck I.L., McKeown M.G., Omanson R.C., Pople M.T. Improving the comprehensibility of stories: The effects of revisions that improve coherence. Reading Research Quarterly. 1985; 19(3):263.

[6] Brown G., Yule G. Discourse Analysis. Cambridge: Cambridge University Press; 1983.

[7] Bublitz W. Cohesion and Coherence [A]. In Zienkowski J., Östman J., Verschueren J. (eds.). Discursive Pragmatics [C]. Amsterdam/Philadelphia: John Benjamins Publishing Company; 2011.

[8] Canale M., Swain M. Theoretical bases of communicative approaches to second language teaching and testing. $A p$ plied Linguistics. 1980; 1(1): 1-47.

[9] Carrell P.L. Cohesion is not coherence. TESOL Quarterly. 1982; 16(4): 479-488.

[10] Carrell P.L. The effects of rhetorical organization on ESL readers. TESOL Quarterly. 1984; 18(3): 441-469.

[11] Carrell P.L. Facilitating ESL reading by teaching text structure. TESOL Quarterly. 1985; 19(4): 727-752.

[12] Cheng X., Steffensen M.S. Metadiscourse: A technique for improving student writing. Research in the Teaching of English. 1996; 30(2):149-181.

[13] Common Core State Standards Initiative. Common Core State Standards for English Language Arts \& Literacy in History/Social Studies, Science, and Technical Subjects. Available from: http://www.corestandards.org/wp-content/ uploads/ELA Standards1.pdf.

[14] Cook G. Discourse. Oxford: Oxford University Press; 1989.

[15] Council of Europe. Common European Framework of Reference for Languages: Learning, Teaching, Assessment. Available from: https://rm.coe.int/1680459f97.

[16] Grabe W., Kaplan R.B. Theory and Practice of Writing: An Applied Linguistics Perspective. Harlow: Pearson Education; 1996.

[17] Gundel J.K. Left Dislocation and The Role of Topic-comment Structure in Linguistic Theory. Columbus: Ohio State University Press; 1975

[18] Halliday M.A.K. An Introduction to Functional Grammar. London: Arnold; 1985.

[19] Halliday M.A.K., Hasan R. Cohesion in English. London: Longman; 1976.

[20] Halliday M.A.K., Matthiessen C., Halliday M. An Introduction to Functional Grammar. London: Routledge; 2014.

[21] Hatch, E. Discourse and Language Education. Cambridge: Cambridge University Press; 1992.

[22] Hoey M. Patterns of Lexis in Text. Oxford: Oxford University Press; 1991.

[23] Kopple W.J.V. Something old, something new: Functional sentence perspective. Research in the Teaching of English. 1983; 17(1): 85-99.

[24] Lee I. Teaching coherence to ESL students: A classroom inquiry. Journal of Second Language Writing. 2002; 11(2): 135-159.

[25] McCarthy M. Discourse Analysis for Language Teachers. Cambridge: Cambridge University Press; 1991.

[26] McCutchen D., Perfetti C.A. Coherence and connectedness in the development of discourse production. Text-Interdisciplinary Journal for the Study of Discourse. 1982; 2(1-3): 113-140.

[27] Minsky M. A Framework for Representing Knowledge [A]. In Winston P. H. (ed.). The Psychology of Computer Vision [C]. New York: McGraw-Hill Book; 1975.

[28] Nuttall C. Teaching reading skills in a foreign language. London: Heinemann Educational; 1982.

[29] Nuttall C. Teaching reading skills in a foreign language. London: Macmillan Publishers; 2005.

[30] Oshima A., Hogue A. English Academic Writing. Harlow: Pearson Education;1991.

[31] Roller C.M. Commentary: The interaction between knowledge and structure variables in the processing of expository prose. Reading Research Quarterly. 1990; 25(2): 79-89.

[32] Seidlhofer B., Widdowson H. Coherence in Summary: The Contexts of Appropriate Discourse [A]. In Bublitz W., Lenk U., Ventola E. (eds.). Coherence in Spoken and Written Discourse[C]. Amsterdam: John Benjamins; $1999 .$.

[33] Thornbury S. Beyond the Sentence: Introducing Discourse Analysis. Oxford: Macmillan; 2005.

[34] Van Dijk T.A., Kintsch W., Van Dijk T.A. Strategies of Discourse Comprehension. New York: Academic Press; 1983.

[35] Widdowson H.G. Teaching Language as Communication. Oxford: Oxford University Press; 1978. 